\title{
Public Perceived Effects of 2022 Winter Olympics on Host City Sustainability
}

\author{
Gulijiazi Yeerkenbieke ${ }^{1,2}$, Chunci Chen ${ }^{1,2}$ and Guizhen $\mathrm{He}^{1,2, * \text { (D) }}$ \\ 1 Research Centre for Eco-Environmental Sciences, State Key Laboratory of Urban and Regional Ecology, \\ Chinese Academy of Sciences, Beijing 100085, China; gulijiazi2018@163.com (G.Y.); \\ 15501267868@163.com (C.C.) \\ 2 College of Resources and Environment, University of Chinese Academy of Sciences, Beijing 100149, China \\ * Correspondence: gzhe@rcees.ac.cn; Tel.: +86-10-6284-4160
}

Citation: Yeerkenbieke, G.; Chen, C.; He, G. Public Perceived Effects of 2022 Winter Olympics on Host City Sustainability. Sustainability 2021, 13, 3787. https://doi.org/10.3390/ su13073787

Academic Editor: Andrea Appolloni

Received: 15 February 2021

Accepted: 25 March 2021

Published: 29 March 2021

Publisher's Note: MDPI stays neutral with regard to jurisdictional claims in published maps and institutional affiliations.

Copyright: (c) 2021 by the authors. Licensee MDPI, Basel, Switzerland. This article is an open access article distributed under the terms and conditions of the Creative Commons Attribution (CC BY) license (https:/ / creativecommons.org/licenses/by/ $4.0 /)$.

\begin{abstract}
Sustainability is now fully integrated into the entire life cycle of the Olympic Games. The planning, preparation, and staging of the Winter Olympics have opportunities to create a sustainable legacy for the host cities for decades. The tangible and/or intangible impacts of the Winter Olympics on the host city are multidimensional, including economic, social, and environmental aspects. However, there are still few studies on the multidimensional impact of the Winter Olympics on the sustainable development of the host city. This paper aims to investigate the effects of the 2022 Winter Olympics on host city sustainability from public perspective. Using a survey of 806 host residents in Beijing and Zhangiiakou, the authors performed descriptive statistics and regression analysis to analyze the effects of the Winter Olympic Games on the city's sustainable development. The Winter Olympic Games are divided into three stages, including the pre-game phase, in-game phase, and post-game phase, and the impacts cover three dimensions, including economic, social, and environmental aspects. The results show that the 2022 Winter Olympics integrate sustainability into the whole process of the Winter Olympics; the Winter Olympics have an important catalytic effect on the host city's sustainable development.
\end{abstract}

Keywords: Winter Olympics; sustainability; public perspective; host city

\section{Introduction}

Mega-events, such as the Olympic Games and World Expos, work as triggers for local development and bring (in-) tangible advantages to the host city and country [1,2]. The Olympic Games, including the Summer and Winter Olympic Games, have emerged as a crucial tool of urban and regional renewal through their ability to justify redevelopment and enhancement, attract inward investment, promote tourism, and create new images for host cities [3]. Over the past decades, more and more host countries have recognized the role of the Olympic Games as catalysts on their path to sustainability [4]. Looking back at the history of the Olympic Games, the 1994 Lillehammer Winter Olympics is considered the first international sporting event to seek to host sustainable games [5]. The 1999 Olympic Agenda 21 states that the Olympic Movement is committed to promoting global sustainable development. In 2010, the Vancouver Organizing Committee for the Olympic Games established the Sustainable Development and Resource Management Commission, which included environmental sustainability as one of its core strategies. In late 2014, the International Olympic Committee (IOC) released the Olympic Agenda 2020, placing sustainable development at the heart of the Olympic Movement. Following the release of the United Nations 2030 Agenda for Sustainable Development in 2015, the IOC expressed its support and in the same year established the Sustainable Development and Legacy Commission with a dedicated Sustainable Development Department. In January 2017, the IOC released the Sustainable Development Implementation Strategy, which set out the principles of practice for the IOC, the Olympic Games, and the Olympic Movement in their 
work on sustainable development [6]. By the time of the 2018 Winter Olympics, Pyeong Chang released eight sustainability-related reports that incorporated legacy management into the sustainability strategy [7].

With the 2022 Beijing Winter Olympics, Beijing will be the only city so far to have hosted both Summer and Winter Games. As the first Olympic Games to put the Olympic Agenda 2020 into practice from the very beginning of the bid process, Beijing 2022 will follow the IOC's guidance and set Beijing's standards for sustainable development. The implementation of the National Strategy of Integrated and Coordinated Development of the Beijing-Tianjin-Hebei Region (hereafter National Strategy), which has been proposed and promoted personally by Chinese President Xi Jinping, gives Beijing 2022 an unparalleled opportunity. The 2022 Beijing Winter Olympic Games will provide a source of power for the integrated development of the Beijing-Tianjin-Hebei region and will lead to deeper economic, political, and cultural development in the three regions, as well as closer ties between China and peace-loving countries or regions in the world [8].

While many studies have been undertaken on the impact of the Olympic Games, most of them have focused on the economic dimension and neglected the social and environmental dimensions [9-11], only in recent years have they started to focus on the social aspects [12-14]. Through a review of the literature, few studies have focused on all three dimensions of impact simultaneously: economic, social, and environmental $[15,16]$. Therefore, we start with three dimensions, namely, the impact of the Winter Olympics on economic, social, and environmental sustainability. Furthermore, this paper covers the impact of the Winter Olympics on the host city at different stages, i.e., before, during, and after the games. Then we evaluate the impact of the Winter Olympics entirely from the public's perspective. This is because the Olympic Games impact studies often ignore intangible impacts, which are based on typically perceived effects and the general attitudes of the populations involved [17]. More generally, evaluations of the Olympic Games can be unconvincing and largely inconclusive if participants' attitudes and beliefs are not considered in the evaluation [17,18]. Over time, residents' interactions with the Olympics and their experiences may change their assessment of whether the Olympics are worth hosting $[19,20]$. Furthermore, we get firsthand data from the questionnaire to illustrate our point. Most prior studies evaluating the impact of the Olympic Games on host sites have relied on secondary data, such as statistical and economic data and estimates of environmental impact $[21,22]$. Only a few studies have investigated residents' perceptions of the impact of the Olympic Games based on primary data [15].

We aim to conduct a comprehensive analysis from the public perspective through questionnaires, descriptive statistics and linear regression: (i) to study the impact of the Winter Olympics on the sustainability of the host city in three phases, including the pre-game phase, the in-game phase and the post-game phase, and in dimensions including economic, social and environmental dimensions; (ii) to enrich theoretically the impact of major events in China and the world on the host sustainability, contributing best practices not only for the sustainability of the Beijing 2022 Winter Olympics, but also for the sustainability of the international Olympic Movement. To achieve this goal, we give our research questions: Will the 2022 Winter Olympics have a positive impact on the sustainability of the host city? and How will the economic, social and environmental sustainability of the 2022 Winter Olympics affect the sustainability of the host city? The article begins with a theoretical background about the sustainability of the Olympic Games and its impact on the host region and offers hypotheses in Section 2. Section 3 presents the conceptual framework and data collection and analysis. Four specific research findings form Section 4 of the article. It concludes with a discussion and summary in Section 5.

\section{Theoretical Background and Hypotheses}

The Olympic Games are marked by global publicity, attract large numbers of international visitors, and are associated with large-scale economic, social, environmental impacts, even urban and regional redevelopment $[1,4,23]$. Their many benefits and costs to the host 
destination in the short and long terms are often cited as catalysts for development [24]. A large portion of national and international scholars' research on the Winter Olympics explores the economic and social benefits of the event. The impact of the Winter Olympics on the organizers may be both positive and negative [25]. The positive economic benefits of the Winter Olympics are mainly in terms of increased local government revenues, economic benefits to the sports industry and tourism, stimulation of consumption, media exposure, enhancement of the image of the host country, and promotion of employment [26-29]. For example, business and tourism were promoted by the Calgary Winter Olympics and the prosperity of the hotel and restaurant industry was brought about by the Salt Lake City Winter Olympics [30-32]. The economic impact of the Winter Olympics also has amplification and multiplier effects [33,34]. Negative economic impacts and potential risks include economic burden, city image, tourism, and ineffective post-event use of stadiums [35-37].

The Winter Olympics brought both positive and negative social impacts on host sites [38-40]. The potential positive impacts of the Olympics on host sites are often cited as increasing community pride, promoting sports participation, improving city image, and upgrading infrastructure $[40,41]$. For example, the Calgary Winter Olympics enhanced the city's image and the 1998 Nagano Olympics had a positive impact on the lives of residents [42,43]. There was a significant increase in media consumption at the Sochi 2014 Winter Olympics, and Winter Olympics had an impact on nationalization in the United States [44]. The main negative social impacts of the Winter Olympic Games event are invasions, nuisance problems, waste of social resources, mass incidents, and inconvenience to residents during the event $[45,46]$.

Few studies have indeed been conducted on the environmental impact of the Winter Olympics. The positive environmental impacts of the Winter Olympics include accelerating the implementation of environmental planning in cities, promoting ecological and environmental management, and arousing public awareness of environmental protection [47-49]. For example, the 2022 Winter Olympics will be used as an opportunity to promote green development in the northern part of Beijing, to promote the construction of white snow and ice industry and green industries, and to promote environmental protection through the medium of the Beijing Winter Olympics [50]. The Winter Olympics may have negative impacts on the environment, such as damage to the natural environment from land-use changes, facility construction and transportation; emissions to soil, air, and water, and the generation of large amounts of waste; ozone depletion, global warming, and air pollution; and the reduction of biodiversity [51-57]. However, the organizers of the Winter Olympics are seeking to minimize negative environmental impacts and maximize positive environmental impacts. Besides, the design and construction of the Winter Olympics and its facilities represent an important opportunity to raise the level and awareness of urban environmental and sustainability issues [58].

The sustainable development practices of the Winter Olympics have gradually evolved from the greening of stadium construction, ecological protection, biodiversity conservation, and the promotion of environmental sustainability to economic sustainability and social sustainability [59]. Compared with urban development in the usual sense, the urban changes triggered by the Winter Olympics are a process with a long period and a wide range of influence. The impact of the Winter Olympics on the host city is multidimensional, greatly shortening the urban planning and construction cycle, accelerating the urban renewal and transformation process, and becoming a powerful booster for its economic growth and transformation, infrastructure improvement, industrial and social restructuring, urban function upgrading, competitiveness enhancement, tourism development, and city visibility, which is a way to promote the leapfrog development of the city [60-64]. Especially, promoting a more integrated urban sustainable development is one of the goals of the 2022 Winter Olympics. The Winter Olympic Games greatly enhanced the level of accessibility between Beijing and Zhangjiakou by the 174-km-long Beijing-Zhangjiakou High-Speed Railway completed in 2019. With a maximum speed of $350 \mathrm{~km}$ per hour, the HSR connects downtown Beijing with Yanqing District and Zhangjiakou within one hour. 
Residents are the direct and ultimate owners of major events. Since the outcome of the event is not static but dynamic, residents' evaluations of the impact of the event will change over time $[65,66]$. The Olympic Games are not only about cities and global processes but also about people's life experiences. Public participation and the level of support from residents are important factors in the success and sustainability of the Winter Olympics. For example, the Calgary Winter Olympics promoted public awareness [42]. In the 1980s, Ritchie and Aitken et al. conducted a systematic study on the attitudes and reactions of residents toward the Calgary Winter Olympics [39,67-69], and Deccio and Baloglu investigated the reactions of non-host city residents toward the 2002 Winter Olympics [38]. Hiller and Wanner focused solely on the public perception of the Vancouver Winter Olympics in the host city [19]. Karadakis et al. studied the issue of visible heritage themes and resident awareness among host and non-host city residents before, during, and after the Vancouver Winter Olympics [70]. Citizens can contribute to the improvement of civic awareness and citizenship in government and the public through orderly participation in the expression of rights, assumption of responsibilities, and broad participation in these world-class events [71]. Residents recognized the importance of and support for the 2022 Winter Olympics, but their participation in activities related to the Beijing 2022 Winter Olympics was low [72]. Right now, Beijing is counting down the days until the Winter Olympics. With the increased publicity and activities for citizens, schools, communities, and cities following the Winter Olympics, the recognition and participation of the host residents have increased dramatically.

In general, the impacts of the Winter Olympic Games on the host venue are multifaceted and multidimensional, and some will even be different at different stages. These impacts can be assessed in terms of economic, environmental, and social sustainability impacts, and positive Winter Olympics impacts on urban sustainability. The staging of Beijing 2022 will undoubtedly advance the implementation of the National Strategy of Integrated and Coordinated Development of the Beijing-Tianjin-Hebei Region, making the strategy a new stimulus for China's economic growth and social development, and setting a new model of ecological and sustainable growth of megalopolis clusters in the world. Therefore, based on the above theoretical study (background), from the public perception, we propose the following hypotheses:

Hypothesis 1 (H1). The 2022 Winter Olympics economic sustainability positively affects host city sustainability.

Hypothesis 2 (H2). The 2022 Winter Olympics social sustainability positively affects host city sustainability.

Hypothesis 3 (H3). The 2022 Winter Olympics environmental sustainability positively affects host city sustainability.

Hypothesis 4 (H4). The 2022 Winter Olympics positively affects host city sustainability.

\section{Conceptual Framework, Data Collection, and Analysis}

\subsection{Hypothesized Framework}

The hypothesized framework for this analysis is presented in Figure 1 . The 2022 Winter Olympics' role in urban sustainability in the public perception is encapsulated in H1-H4. Three phases named pre-game, in-game, and post-game of the Beijing Winter Olympics, that is, the entire life cycle, were studied through the three dimensions of economy, society, and environment. The four hypotheses were used to determine whether hosting the Winter Olympics will promote the sustainable development of the host city from the perspective of the public. 


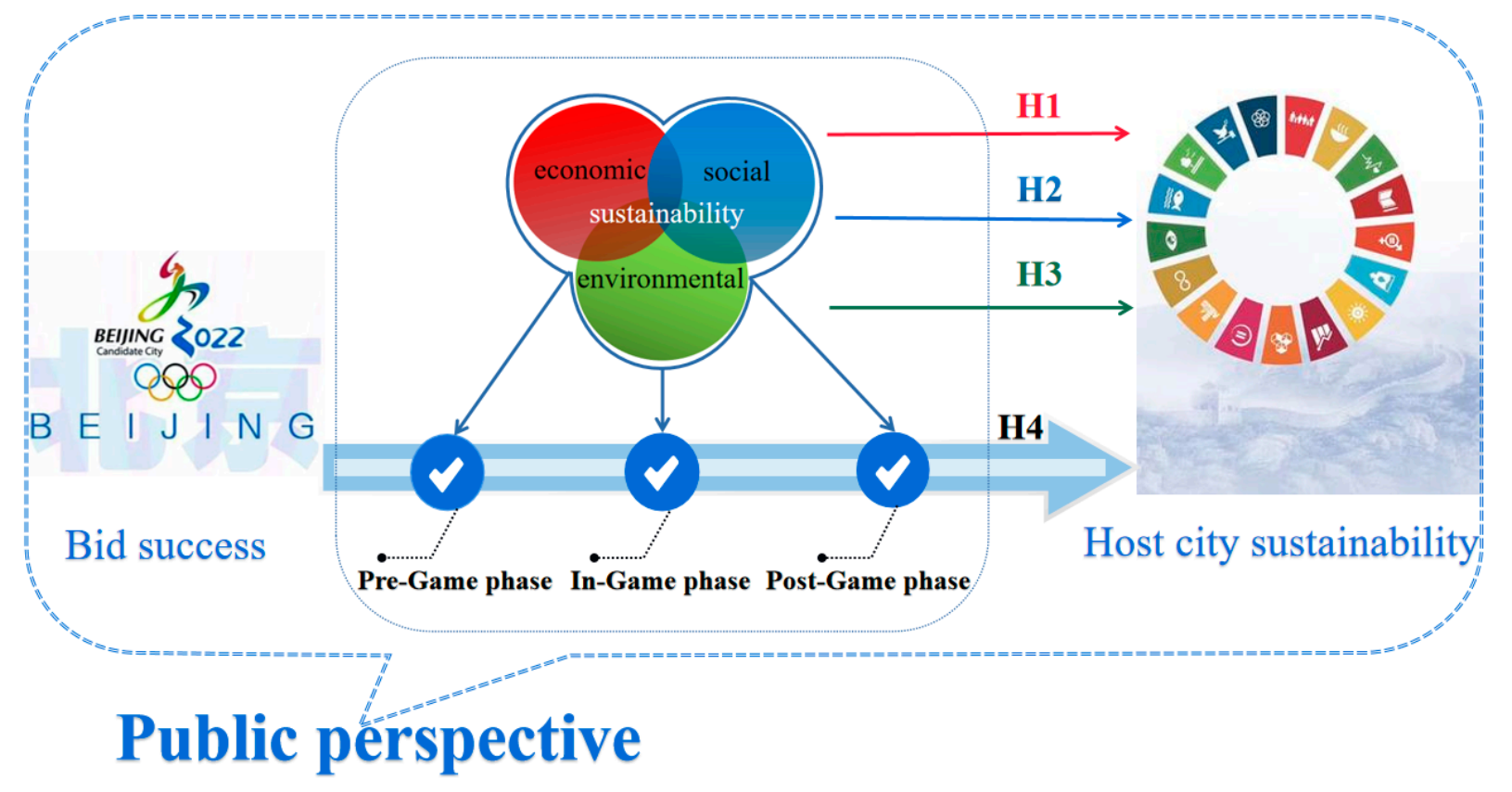

Figure 1. Hypothesized framework.

\subsection{Study Area}

Beijing and Zhangjiakou in Hebei Province were awarded 2022 Olympic Winter Games in July 2015 after 20 months' application and evaluation procedures, with the ice events to be held in Beijing and the snow events to be held in Chongli District, Zhangjiakou. The vision and concepts of Beijing 2022, which are in agreement with the development of the Beijing-Zhangjiakou Sport, Culture, and Tourism Belt, have won all-round backing from the national and local governments. The sustainability drive for Beijing 2022 includes the following six areas: fulfilling the Beijing 2022 sustainability commitments, establishing a sustainability management system, ensuring sustainable management of venues, implementing sustainable procurement, accelerating low-carbon development, and strengthening communication and public engagement [72]. In 2018, the Beijing 2022 Sustainable Development Committee was established. On 15 May 2020, the IOC, the International Paralympic Committee (IPC), and the Beijing Winter Olympic Organizing Committee simultaneously released the Beijing 2022 Winter Olympics and Paralympic Winter Games Sustainability Plan. The Sustainability Plan aims to further strengthen the top-level design, integrate and promote the sustainability of the Beijing Winter Olympic Games. The Plan defines the vision of the Beijing Winter Olympics as "sustainable and future-oriented". It proposes 12 actions, 37 tasks, and 119 measures in three areas: positive environmental impact, new regional development, and better living. It not only reflects the concept of "green, shared, open and clean", but also demonstrates the reform spirit of the Olympic Agenda 2020.

The study area for this research was Beijing and Zhangjiakou-two host cities of the 2022 Winter Olympics. A total of 25 venues are planned to be used for the 2022 Winter Olympics, spread over three regions, Beijing city center, Yanqing County of Beijing, and Chongli District in Zhangjiakou. The Beijing 2008 Olympic Games provided the city of Beijing with world-class venues, while Zhangjiakou in recent years has witnessed dramatic improvements in ski facilities. In order to integrate the holding of the Olympic Winter Games with the development of the environment, economy, and society, Beijing 2022 will promote the establishment of a sustainability management mechanism, setting up a model of mutual benefit and win-win development between the Olympic Movement and the host city.

The geographical distribution of the 806 respondents who participated in this research is shown in Figure 2, and the distribution of people was as follows (numbers in paren- 
theses). There are 16 districts and two counties in Beijing, and we selected the following four districts and one county according to the distribution of venues and the distribution of respondents: Chaoyang District (101), Haidian District (101), Shijingshan District (101), Xicheng District (101), and Yanqing County (100). Zhangjiakou was divided into three categories: downtown, Chongli County, and other counties, and the distribution of respondents: downtown Zhangjiakou (83), Chongli County (101), and other counties (118).

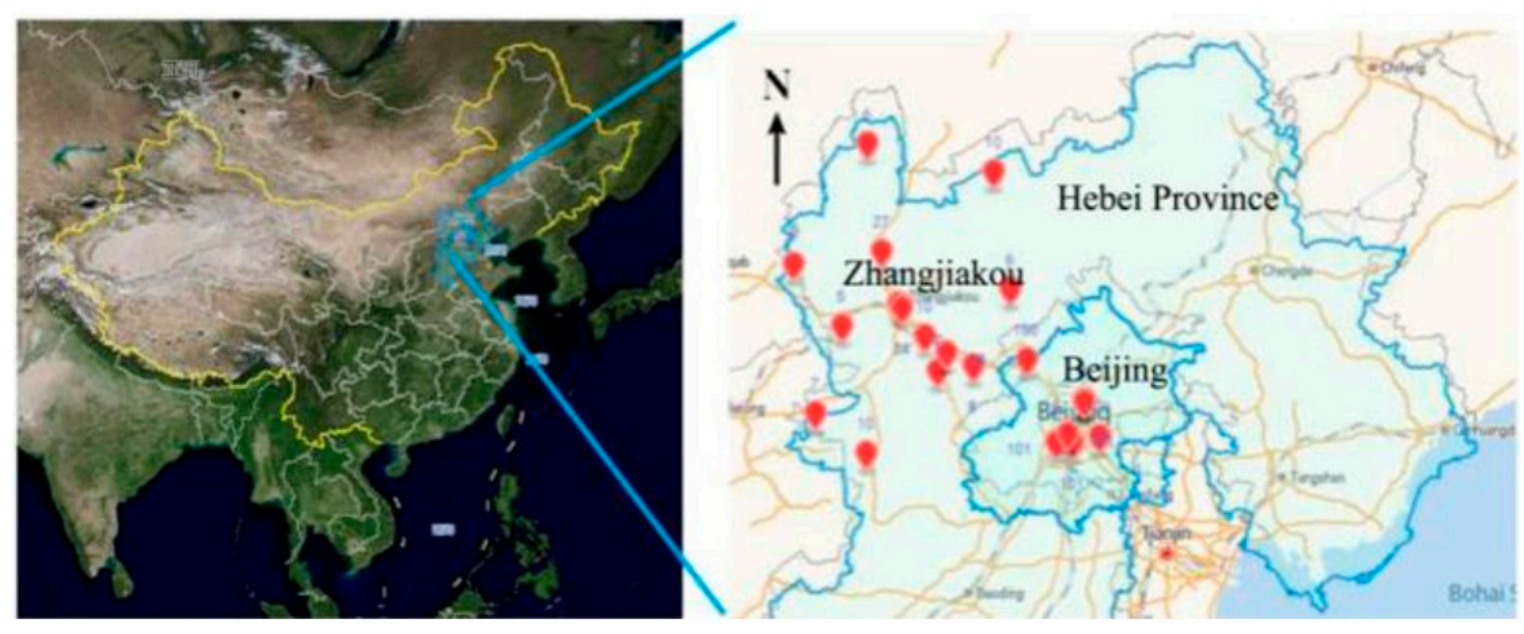

Figure 2. Map of survey locations. All red dots indicate the locations of respondents (district/county level).

\subsection{Data Collection}

The official documents review and government websites were used for related information collection. We prepared the questionnaire design with reports on the Beijing Winter Olympics bid, the official website of the Winter Olympics, and reports on local planning on the official websites of Beijing and Zhangjiakou. From July to September 2019, the draft questionnaire was designed by the corresponding author, discussed by internal experts, peer discussions, and experts from the survey company. Finally, the questionnaire was divided into two sections: the impact of the Winter Olympics on sustainable development, and the basic information of interviewees. The formal face-to-face questionnaire surveys were conducted by a GR Survey Company in Fuzhou, China. The survey population was randomly selected, and our study included residents who had no access to the Internet and people interested in the survey and questions. Five investigators surveyed 820 residents from 20 October to 20 November 2019. The respondents were some ordinary residents of Beijing and Zhangjiakou City, Hebei Province, who were able to complete the questionnaire in normal order and were judged to be qualified for the questionnaire. Finally, a total of 806 valid questionnaires were returned from the initial 820 sent out.

\subsection{Data Analysis}

The data obtained from the questionnaire were first organized and the questionnaire answers were collected using Microsoft Excel. All responses were coded to summarize the data. There were 20, 21, and 31 items on the economic, social, and environmental sustainability of the Winter Olympics, and 10 items on city sustainability. Each item was also divided into three phases, namely the pre-game phase, the in-game phase, and the post-game phase. A total of 806 respondents rated their level of agreement for each phase of each item, with three levels of agreement, " 1 " being low, " 2 " being medium, and " 3 " being high. Each respondent's basic information was divided into seven areas: location, distance, gender, age, education, occupation, and income (Table 1). Data were processed first by entering the data into a file in SPSS 26.0 software and assigning each variable accordingly to the actual situation. 
Table 1. Social and demographic background of the respondents.

\begin{tabular}{|c|c|c|c|c|c|c|}
\hline \multirow{2}{*}{ Variables } & \multicolumn{2}{|c|}{ Beijing $(\mathrm{N}=504)$} & \multicolumn{2}{|c|}{ Zhangjiakou (N = 302) } & \multicolumn{2}{|c|}{ Total $(\mathrm{N}=806)$} \\
\hline & Frequency & Percent (\%) & Frequency & Percent (\%) & Frequency & Percent $(\%)$ \\
\hline \multicolumn{7}{|l|}{ Gender } \\
\hline Male & 288 & 57.14 & 214 & 70.86 & 502 & 62.28 \\
\hline $\begin{array}{c}\text { Female } \\
\text { Age }\end{array}$ & 216 & 42.86 & 88 & 29.14 & 304 & 37.72 \\
\hline $15-19$ & 7 & 1.39 & 17 & 5.63 & 24 & 2.98 \\
\hline $20-29$ & 226 & 44.84 & 162 & 53.64 & 388 & 48.14 \\
\hline $30-39$ & 217 & 43.05 & 95 & 31.46 & 312 & 38.71 \\
\hline $40-49$ & 45 & 8.93 & 25 & 8.28 & 70 & 8.69 \\
\hline 50-59 & 9 & 1.79 & 2 & 0.66 & 11 & 1.36 \\
\hline 60 and over & 0 & 0.00 & 1 & 0.33 & 1 & 0.12 \\
\hline \multicolumn{7}{|l|}{ Education } \\
\hline Middle school or below & 7 & 1.39 & 9 & 2.98 & 16 & 1.98 \\
\hline High school & 54 & 10.71 & 51 & 16.89 & 105 & 13.03 \\
\hline University & 404 & 80.16 & 235 & 77.81 & 639 & 79.28 \\
\hline Master's degree or above & 39 & 7.74 & 7 & 2.32 & 46 & 5.71 \\
\hline \multicolumn{7}{|l|}{ Occupation } \\
\hline Farmer & 9 & 1.78 & 10 & 3.31 & 19 & 2.36 \\
\hline Government staff & 46 & 9.13 & 41 & 13.58 & 87 & 10.79 \\
\hline Company employee & 264 & 52.38 & 107 & 35.43 & 371 & 46.03 \\
\hline Teacher and researcher & 50 & 9.92 & 25 & 8.28 & 75 & 9.31 \\
\hline Retired & 0 & 0.00 & 0 & 0.00 & 0 & 0.0 \\
\hline Self-entrepreneur & 90 & 17.86 & 52 & 17.22 & 142 & 17.62 \\
\hline Student & 43 & 8.53 & 63 & 20.86 & 106 & 13.15 \\
\hline Others & 2 & 0.40 & 4 & 1.32 & 6 & 0.74 \\
\hline \multicolumn{7}{|l|}{ Monthly Household Income } \\
\hline Below CNY $2000^{a}$ & 39 & 7.74 & 55 & 18.21 & 94 & 11.66 \\
\hline CNY 2000-3999 & 32 & 6.35 & 33 & 10.93 & 65 & 8.07 \\
\hline CNY 4000-5999 & 84 & 16.67 & 80 & 26.49 & 164 & 20.35 \\
\hline CNY 6000-7999 & 160 & 31.75 & 66 & 21.86 & 226 & 28.04 \\
\hline CNY 8000-9999 & 102 & 20.24 & 43 & 14.24 & 145 & 17.99 \\
\hline CNY 10,000-14,999 & 66 & 13.09 & 21 & 6.95 & 87 & 10.79 \\
\hline CNY 15,000-19,999 & 15 & 2.97 & 4 & 0.66 & 17 & 2.11 \\
\hline CNY 20,000 or more & 6 & 1.19 & 2 & 0.66 & 8 & 0.99 \\
\hline \multicolumn{7}{|l|}{ Distance (Home-Venue) } \\
\hline$<5 \mathrm{~km}$ & 27 & 5.36 & 9 & 2.98 & 36 & 4.47 \\
\hline $6-10 \mathrm{~km}$ & 54 & 10.71 & 22 & 7.28 & 76 & 9.43 \\
\hline $11-20 \mathrm{~km}$ & 85 & 16.87 & 26 & 8.61 & 111 & 13.77 \\
\hline $21-30 \mathrm{~km}$ & 99 & 19.64 & 68 & 22.52 & 167 & 20.72 \\
\hline $31-40 \mathrm{~km}$ & 76 & 15.08 & 51 & 16.89 & 127 & 15.76 \\
\hline $41-50 \mathrm{~km}$ & 60 & 11.90 & 37 & 12.25 & 97 & 12.03 \\
\hline$>50 \mathrm{~km}$ & 103 & 20.44 & 89 & 29.47 & 192 & 23.82 \\
\hline
\end{tabular}

Note: $\mathrm{N}=806{ }^{\text {a }}$ One US dollar (USD) was approximately equivalent to 6.768 Chinese Yuan (CNY) at the time of this study.

According to Beijing census data in 2010, the rate of males and females was 51.6\% and $48.4 \%$ respectively. The rates of people with education at primary /middle school, high school, and university and over were $43.1 \%, 22.1 \%$, and $32.8 \%$, respectively. The people at $15-29,30-49$, and $50-64$ years old were $28.7 \%, 37.5 \%$, and $16.6 \%$, respectively. According to Zhangjiakou census data in 2010, the rates of males and females were $51.2 \%$ and $48.8 \%$, respectively. The rates of people with education at primary, middle school, high school, and university and over were $29.6 \%, 39.1 \%, 13.5 \%$, and $6.8 \%$, respectively. The people at $0-14,15-64$, and more than 64 years old were $15.9 \%, 73.7 \%$, and $10.3 \%$, respectively.

We divided each of the three parts of the items into several dimensions. First of all, we divided the 20 economic sustainability-related items into six dimensions: economic development, industry development, price rising, construction costs, tournament commodity consumption, and investment benefits. In addition, we divided 21 economic sustainability- 
related items into eight dimensions: urban development, community development, social security, social welfare (positive), social welfare (negative), residents' rights and interests (positive), residents' rights and interests (negative), and cultural protection. Finally, we divided the 31 economic sustainability-related items into nine dimensions: resource conservation (positive), resource conservation (negative), energy use, living environment, environmental pollution, tourism resources (positive), tourism resources (negative), and biodiversity. We finally performed descriptive statistics for all items and dimensions of the three phases and the 10 items of city sustainability. The descriptive statistics yielded the mean and standard deviation of the agreement for each item and dimension.

A linear regression analysis was performed on SPSS with urban sustainability as the dependent variable and the dimensions as factors. One model per dimension per phase was obtained, for a total of 12 models, to test our hypothesis. In statistics, linear regression is a type of regression analysis that models the relationship between one or more independent and dependent variables using a least square function called a linear regression equation. This function is a linear combination of one or more model parameters called regression coefficients. Given a dependent variable and a number of independent variables that are potentially correlated with the dependent variable, linear regression analysis can be used to quantify the strength of the correlation between the dependent and independent variables [73]. We performed correlation validation on our data before conducting linear regression analysis. After confirming that there was a linear relationship between the dependent and independent variables, that the data conformed to a normal distribution, that there was no multicollinearity, no auto correlation, and no homoscedasticity, it was concluded that our data were eligible for linear regression analysis. In the Results section, we give $R^{2}$ and $F$ values to test our obtained models.

\section{Results}

The economy, society, and the environment are three pillars of sustainable development. The main focus here is environmental sustainability; however, there is inevitably cross-penetration into the economic and social aspects of sustainability [62]. Despite the fact that the 2022 Winter Olympics have not yet been held, respondents to our survey were asked to what extent the 2022 Winter Olympics will play a role in the sustainability of the host city before, during and after the games. Although this did not represent their thoughts during or after the games, their expectations and perceptions of the process during and after the games were indicative of the impact of hosting the Winter Olympics on the sustainability of the host city from the public's perspective.

\subsection{Winter Olympics Economic Sustainability}

Big cities regard major events as an important way to realize the leapfrog development of the tourism economy [74]. The emergence of the Olympic Games was seen as a means to significantly boost the economy of the host city and build its existing image [75]. To further understand the impact of the Winter Olympics on the sustainable economic development of the host city, we conducted a study from the public's perspective to obtain the following results (Figure 3 and Table 2). All items are listed in Figure 3 according to the progressive increase in the frequency of the pre-game phase, while Table 2 shows the mean and standard deviation of all items.

Above all, in the pre-game phase, residents gave a high level of agreement for boosting tourism development and consumption $(\mathrm{M}=2.57)$ and providing more business opportunities for local businesses $(M=2.53)$. Mixed responses were given regarding whether the Winter Olympics would increase local financial burden by large investments $(\mathrm{SD}=0.75)$ and occupy other budgets from the public sector $(\mathrm{SD}=0.75)$. Residents expressed a high level of agreement toward the industry development dimension $(\mathrm{M}=2.48)$. Items with lower mean scores (below 2.1) were associated with idling of infrastructure and occupying other budgets from the public sector. 
Pre-Game phase In-Game phase Post-Game phase

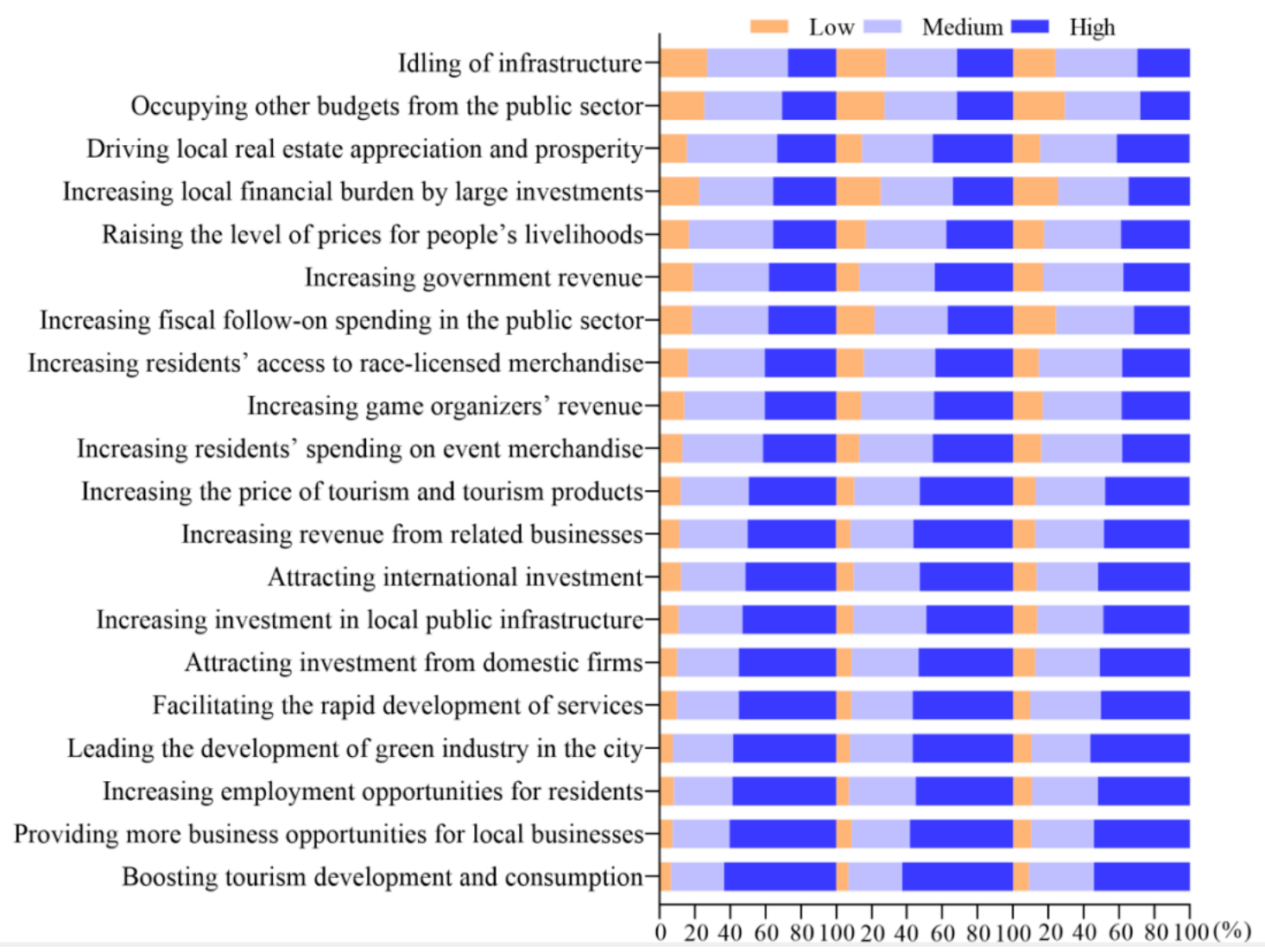

Figure 3. The perceived economic sustainability of the 2022 Winter Olympics. $N=806$; all items were assessed on a three-point scale $(1=$ low, 2 = medium, and 3 = high $)$.

Table 2. Descriptive statistics of the 2022 Winter Olympics economic sustainability.

\begin{tabular}{|c|c|c|c|c|c|c|}
\hline \multirow{2}{*}{ Economic Sustainability Dimensions \& Items } & \multicolumn{2}{|c|}{ Pre-Game Phase } & \multicolumn{2}{|c|}{ In-Game Phase } & \multicolumn{2}{|c|}{ Post-Game Phase } \\
\hline & $\mathbf{M}$ & SD & $\mathbf{M}$ & SD & $\mathbf{M}$ & SD \\
\hline Dimension 1: economic development & 2.32 & 0.48 & 2.36 & 0.46 & 2.28 & 0.50 \\
\hline Increasing government revenue & 2.19 & 0.73 & 2.31 & 0.69 & 2.21 & 0.71 \\
\hline Increasing employment opportunities for residents & 2.50 & 0.65 & 2.48 & 0.63 & 2.41 & 0.68 \\
\hline Increasing game organizers' revenue & 2.26 & 0.69 & 2.31 & 0.70 & 2.22 & 0.71 \\
\hline Dimension 2: industry development & 2.48 & 0.44 & 2.50 & 0.42 & 2.42 & 0.47 \\
\hline Increasing revenue from related businesses & 2.39 & 0.68 & 2.48 & 0.64 & 2.36 & 0.69 \\
\hline Boosting tourism development and consumption & 2.57 & 0.61 & 2.56 & 0.62 & 2.45 & 0.65 \\
\hline Leading the development of green industry in the city & 2.50 & 0.64 & 2.49 & 0.64 & 2.46 & 0.68 \\
\hline Facilitating the rapid development of services & 2.45 & 0.67 & 2.48 & 0.65 & 2.41 & 0.66 \\
\hline Dimension 3: prices rising & 2.25 & 0.48 & 2.31 & 0.51 & 2.28 & 0.52 \\
\hline Driving local real estate appreciation and prosperity & 2.18 & 0.68 & 2.31 & 0.71 & 2.26 & 0.71 \\
\hline Increasing the price of tourism and tourism products & 2.37 & 0.69 & 2.42 & 0.67 & 2.35 & 0.70 \\
\hline Raising the level of prices for people's livelihoods & 2.19 & 0.70 & 2.21 & 0.71 & 2.21 & 0.72 \\
\hline Dimension 4: construction costs & 2.10 & 0.54 & 2.08 & 0.58 & 2.05 & 0.57 \\
\hline Increasing local financial burden by large investments & 2.13 & 0.75 & 2.09 & 0.77 & 2.09 & 0.77 \\
\hline Increasing fiscal follow-on spending in the public sector & 2.20 & 0.73 & 2.15 & 0.75 & 2.07 & 0.74 \\
\hline Occupying other budgets from the public sector & 2.05 & 0.75 & 2.04 & 0.77 & 1.99 & 0.76 \\
\hline Idling of infrastructure & 2.00 & 0.74 & 2.04 & 0.77 & 2.06 & 0.73 \\
\hline Dimension 5: tournament commodity consumption & 2.26 & 0.58 & 2.30 & 0.58 & 2.23 & 0.58 \\
\hline Increasing residents' spending on event merchandise & 2.28 & 0.68 & 2.32 & 0.69 & 2.22 & 0.70 \\
\hline Increasing residents' access to race-licensed merchandise & 2.24 & 0.71 & 2.28 & 0.72 & 2.24 & 0.69 \\
\hline Dimension 6: investment benefits & 2.45 & 0.46 & 2.44 & 0.45 & 2.39 & 0.51 \\
\hline Attracting investment from domestic firms & 2.45 & 0.67 & 2.45 & 0.65 & 2.38 & 0.70 \\
\hline Attracting international investment & 2.39 & 0.70 & 2.43 & 0.67 & 2.39 & 0.71 \\
\hline Providing more business opportunities for local businesses & 2.53 & 0.63 & 2.50 & 0.65 & 2.44 & 0.67 \\
\hline Increasing investment in local public infrastructure & 2.42 & 0.68 & 2.39 & 0.66 & 2.35 & 0.71 \\
\hline
\end{tabular}

Note: $\mathrm{N}=806$; all items were assessed on a three-point scale $(1=$ low, $2=$ medium, and $3=$ high $)$. 
Furthermore, during the in-game phase, respondents also highly agreed with boosting tourism development and consumption $(\mathrm{M}=2.56)$. Mixed responses were given regarding whether it would increase local financial burden by large investments $(\mathrm{SD}=0.77)$, occupy other budgets from the public sector $(\mathrm{SD}=0.77)$, and idle infrastructure $(\mathrm{SD}=0.77$ ). Residents also expressed a high level of agreement toward the industry development dimension ( $M=2.50)$. Items with lower mean scores (below 2.1) were also associated with idling of infrastructure and occupying other budgets from the public sector.

Last but not least, in the post-game phase, respondents also highly agreed on leading the development of green industry in the city $(\mathrm{M}=2.46)$ and boosting tourism development and consumption $(\mathrm{M}=2.45)$. Mixed responses were given regarding whether it would increase local financial burden by large investments $(\mathrm{SD}=0.77)$, and occupy other budgets from the public sector $(\mathrm{SD}=0.76)$. Residents also expressed a high level of agreement toward the industry development dimension $(\mathrm{M}=2.42)$. Items with lower mean scores (below 2.1) were also associated with occupying other budgets from the public sector.

All hypothesized effects were tested using regression equations. Means of dimensions were used to estimate the effects of Winter Olympics impacts on urban sustainability. We used three models to test H1. Firstly, for the pre-game, in-game, and post-game phases, after estimating Models 1 to 3, we regressed urban sustainability on the dimension of Winter Olympics economical sustainability to test H1. In Table 3 , the results showed that industry development $(p<0.001$ in three stages), prices rising $(p<0.001,0.01,0.001)$, and investment benefits $(p<0.001,0.001,0.05)$ exerted significantly positive effects on host city sustainability $\left(R^{2}=0.404,0.361,0.381\right.$ and $\left.F=91.969,76.851,83.729\right)$. Thus, H1 was partially supported.

Table 3. Regression results of economic sustainability of the 2022 Winter Olympics.

\begin{tabular}{|c|c|c|c|}
\hline Independent Variables & Pre-Game Phase Model 1 (Std $\beta$ ) & In-Game Phase Model 2 (Std $\beta$ ) & Post-Game Phase Model $3($ Std $\beta$ ) \\
\hline Economic development & $0.069 *$ & 0.035 & $0.144^{* * *}$ \\
\hline Industry development & $0.195^{* * *}$ & $0.171^{* * *}$ & $0.254^{* * *}$ \\
\hline Prices rising & $0.174^{* * *}$ & $0.118^{* *}$ & $0.207^{* * *}$ \\
\hline Construction costs & $0.139^{* * *}$ & $0.137^{* * *}$ & 0.057 \\
\hline Tournament commodity consumption & 0.062 & $0.083 *$ & 0.062 \\
\hline Investment benefits & $0.244^{* * *}$ & $0.294^{* * *}$ & $0.089 *$ \\
\hline$R^{2}$ & 0.404 & 0.361 & 0.381 \\
\hline$F$ & 91.969 & 76.851 & 83.729 \\
\hline
\end{tabular}

Note: ${ }^{*}, * * * * *$ Significant at $p<0.05, p<0.01, p<0.001$, respectively.

\subsection{Winter Olympics Social Sustainability}

Through sport, thanks to extensive participation programs, we now have an important source of national identity; national pride resulting from excellence in international and regional competitions; and economic growth through a thriving sports industry program. The prestige and competitive spirit associated with hosting the Olympics may leave a legacy of national pride and solidarity. It can also improve education and raise awareness of cultural values [76]. Let us understand the impacts of the Winter Olympics on the social sustainability of the host city from the public perspective (Figure 4 and Table 4). All items are listed in Figure 4 according to the progressive increase in the frequency of the pre-game phase, while Table 4 shows the mean and standard deviation of all items.

To start with, in the pre-game phase, residents gave a high level of agreement for increasing the city's international reputation and visibility $(\mathrm{M}=2.55)$ and promoting a sense of pride and honor among residents $(\mathrm{M}=2.52)$. Mixed responses were given regarding whether the Winter Olympics would affect public security and increase the crime rate $(\mathrm{SD}=0.82)$ and lead to a widening gap between rich and poor $(\mathrm{SD}=0.80)$. Residents expressed a high level of agreement toward the social welfare (positive) dimension $(\mathrm{M}=2.44)$. Items with lower mean scores (below 1.8) were associated with leading to a widening gap between rich and poor, and affecting public security and increasing the crime rate. 


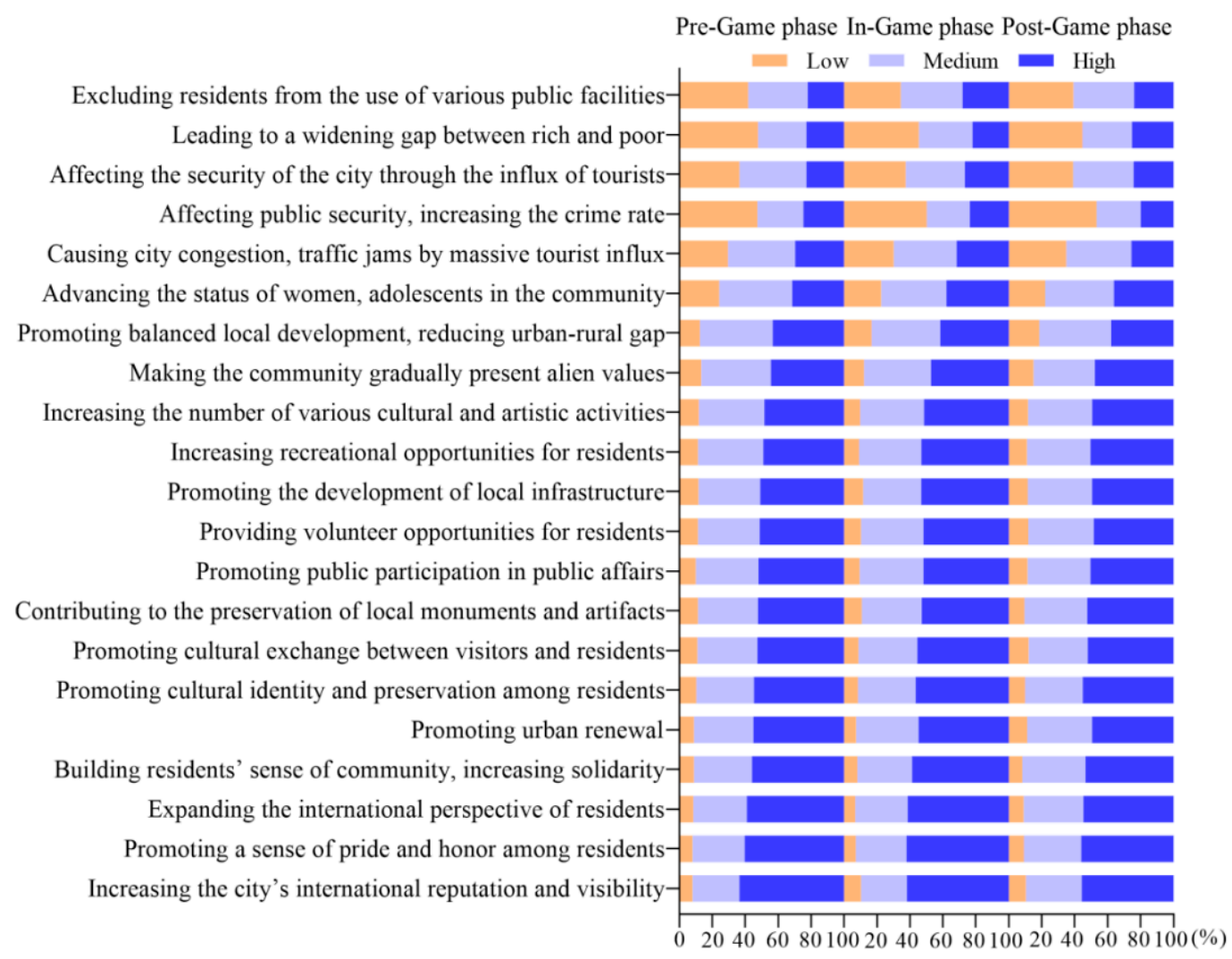

Figure 4. The perceived social sustainability of the 2022 Winter Olympics. N = 806; all items were assessed on a three-point scale $(1=$ low, 2 = medium, and 3 = high $)$.

Table 4. Descriptive statistics of the 2022 Winter Olympics social sustainability.

\begin{tabular}{|c|c|c|c|c|c|c|}
\hline \multirow{2}{*}{ Social Sustainability Dimensions \& Items } & \multicolumn{2}{|c|}{ Pre-Game Phase } & \multicolumn{2}{|c|}{ In-Game Phase } & \multicolumn{2}{|c|}{ Post-Game Phase } \\
\hline & $\mathbf{M}$ & SD & $\mathbf{M}$ & SD & $\mathbf{M}$ & SD \\
\hline Dimension 1: urban development & 2.43 & 0.47 & 2.42 & 0.46 & 2.35 & 0.49 \\
\hline Increasing the city's international reputation and visibility & 2.55 & 0.64 & 2.52 & 0.68 & 2.45 & 0.67 \\
\hline Promoting balanced local development, reducing urban-rural gap & 2.31 & 0.68 & 2.25 & 0.72 & 2.20 & 0.73 \\
\hline Promoting the development of local infrastructure & 2.39 & 0.69 & 2.42 & 0.69 & 2.38 & 0.68 \\
\hline Promoting urban renewal & 2.46 & 0.65 & 2.48 & 0.63 & 2.38 & 0.68 \\
\hline Dimension 2: community development & 2.36 & 0.44 & 2.40 & 0.43 & 2.36 & 0.47 \\
\hline Promoting a sense of pride and honor among residents & 2.52 & 0.64 & 2.55 & 0.62 & 2.47 & 0.66 \\
\hline Building residents' sense of community, increasing solidarity & 2.47 & 0.65 & 2.51 & 0.64 & 2.45 & 0.64 \\
\hline Promoting public participation in public affairs & 2.42 & 0.67 & 2.42 & 0.66 & 2.39 & 0.68 \\
\hline Advancing the status of women, adolescents in the community & 2.07 & 0.74 & 2.16 & 0.76 & 2.14 & 0.75 \\
\hline Making the community gradually present alien values & 2.31 & 0.69 & 2.35 & 0.69 & 2.33 & 0.72 \\
\hline Dimension 3: social security & 1.82 & 0.68 & 1.81 & 0.69 & 1.76 & 0.69 \\
\hline Affecting public security, increasing the crime rate & 1.77 & 0.82 & 1.73 & 0.82 & 1.67 & 0.79 \\
\hline Affecting the security of the city through the influx of tourists & 1.86 & 0.76 & 1.89 & 0.79 & 1.85 & 0.78 \\
\hline Dimension 4: social welfare (positive) & 2.44 & 0.55 & 2.49 & 0.50 & 2.43 & 0.53 \\
\hline Increasing recreational opportunities for residents & 2.38 & 0.68 & 2.44 & 0.65 & 2.39 & 0.68 \\
\hline Expanding the international perspective of residents & 2.50 & 0.65 & 2.55 & 0.62 & 2.46 & 0.65 \\
\hline Dimension 5: social welfare (negative) & 1.75 & 0.80 & 1.77 & 0.79 & 1.81 & 0.81 \\
\hline Leading to a widening gap between rich and poor & 1.75 & 0.80 & 1.77 & 0.79 & 1.81 & 0.81 \\
\hline Dimension 6: residents' rights and interests (positive) & 2.40 & 0.68 & 2.42 & 0.67 & 2.37 & 0.69 \\
\hline Providing volunteer opportunities for residents & 2.40 & 0.68 & 2.42 & 0.67 & 2.37 & 0.69 \\
\hline Dimension 7: residents' rights and interests (negative) & 1.90 & 0.65 & 1.98 & 0.66 & 1.88 & 0.67 \\
\hline Excluding residents from the use of various public facilities & 1.80 & 0.78 & 1.94 & 0.79 & 1.85 & 0.78 \\
\hline Causing city congestion, traffic jams by massive tourist influx & 2.00 & 0.77 & 2.01 & 0.79 & 1.91 & 0.77 \\
\hline Dimension 8: cultural protection & 2.41 & 0.51 & 2.45 & 0.47 & 2.42 & 0.50 \\
\hline Promoting cultural identity and preservation among residents & 2.44 & 0.67 & 2.48 & 0.65 & 2.45 & 0.67 \\
\hline Contributing to the preservation of local monuments and artifacts & 2.41 & 0.68 & 2.42 & 0.68 & 2.43 & 0.66 \\
\hline Increasing the number of various cultural and artistic activities & 2.36 & 0.69 & 2.42 & 0.66 & 2.38 & 0.69 \\
\hline Promoting cultural exchange between visitors and residents & 2.42 & 0.68 & 2.47 & 0.65 & 2.40 & 0.69 \\
\hline
\end{tabular}


In the second place, during the in-game phase, respondents also highly agreed with promoting a sense of pride and honor among residents $(\mathrm{M}=2.55)$ and expanding the international perspective of residents $(\mathrm{M}=2.55)$. Mixed responses were given regarding whether it would affect public security and increase the crime rate $(\mathrm{SD}=0.82)$. Residents also expressed a high level of agreement toward the social welfare (positive) dimension $(\mathrm{M}=2.49)$. Items with lower mean scores (below 1.8) were also associated with affecting public security and increasing the crime rate, as well as leading to a widening gap between rich and poor.

In the post-game phase, finally, the respondents highly agreed about promoting a sense of pride and honor among residents $(\mathrm{M}=2.47)$ and expanding the international perspective of residents $(M=2.46)$. Mixed responses were given regarding whether it would lead to a widening gap between rich and poor $(\mathrm{SD}=0.81$ ). Residents also expressed a high level of agreement toward the social welfare (positive) dimension $(\mathrm{M}=2.43)$. Items with lower mean scores (below 1.8) were also associated with affecting public security and increasing the crime rate.

We also used three models to test H2. For the pre-game, in-game, and post-game phases, after estimating Models 4 to 6, we regressed host city sustainability on the dimension of Winter Olympics social sustainability to test H2. In Table 5, the result showed that urban development $(p<0.001$ in three phases), community development $(p<0.001)$, social security $(p<0.01$ and 0.001$)$, social welfare (positive) $(p<0.01$ and 0.001$)$, social welfare (negative) $(p<0.001$ and 0.01$)$, residents' rights and interests (negative) $(p<0.001$ and 0.05$)$, and cultural protection $(p<0.001)$ exerted significantly positive effects on host city sustainability $\left(R^{2}=0.598,0.566,0.612 ; F=150.601,132.250,159.608\right)$. Thus, $\mathrm{H} 2$ was mostly supported.

Table 5. Regression results of social sustainability of the 2022 Winter Olympics.

\begin{tabular}{|c|c|c|c|}
\hline Independent Variables & Pre-Game Phase Model 4 (Std $\beta$ ) & In-Game Phase Model 5 (Std $\beta$ ) & Post-Game Phase Model $6(\operatorname{Std} \beta)$ \\
\hline Urban development & $0.233 * * *$ & $0.231 * * *$ & $0.235 * * *$ \\
\hline Community development & $0.210 * * *$ & $0.198^{* * *}$ & $0.258^{* * *}$ \\
\hline Social security & $0.103 * *$ & $0.195 * * *$ & $0.141^{* * *}$ \\
\hline Social welfare (positive) & $0.079 * *$ & $0.138 * * *$ & $0.109 * * *$ \\
\hline Social welfare (negative) & $0.126^{* * *}$ & $0.114^{* * *}$ & $0.094^{* *}$ \\
\hline Residents' rights and interests (positive) & 0.011 & $0.091 * *$ & 0.041 \\
\hline Residents' rights and interests (negative) & $0.141^{* * *}$ & $0.061 *$ & $0.136^{* * *}$ \\
\hline Cultural protection & $0.287^{* * *}$ & $0.195^{* * *}$ & $0.203^{* * *}$ \\
\hline$R^{2}$ & 0.598 & 0.566 & 0.612 \\
\hline$F$ & 150.601 & 132.250 & 159.608 \\
\hline
\end{tabular}

Note: ${ }^{*}, * *, * *$ Significant at $p<0.05, p<0.01, p<0.001$, respectively.

\subsection{Winter Olympics Environmental Sustainability}

The basic idea of sustainable development was to live equitably in accordance with the possibilities provided by nature. The goal of sustainable urban development is achieved through planning, implementation of activities, application of science and technology, and the establishment of broad strategic partnerships to achieve environmental, economic, and social sustainability [77]. Lastly, we investigated the impacts of the Winter Olympics on the environmental sustainability of the host city from the public perspective (Figure 5 and Table 6). All items are listed in Figure 5 according to the progressive increase in the frequency of the pre-game phase, while Table 6 shows the mean and standard deviation of all items.

In the pre-game phase, first of all, residents gave a high level of agreement for encouraging the reuse of resources and raw materials $(\mathrm{M}=2.43)$ and encouraging travel by green modes of transportation $(\mathrm{M}=2.43)$. Mixed responses were given regarding whether the Winter Olympics would consume a lot of energy by sports facilities and stadiums $(\mathrm{SD}=0.79)$, cause water pollution $(\mathrm{M}=0.79)$, and occupy and destroy biological habitats $(\mathrm{SD}=0.79)$. Residents expressed a high level of agreement toward the resource conservation (positive) dimension $(\mathrm{M}=2.41)$. Items with lower mean scores (below 1.8) were 
associated with causing chemical contamination, and increasing alien animal, plant species by biological invasions.

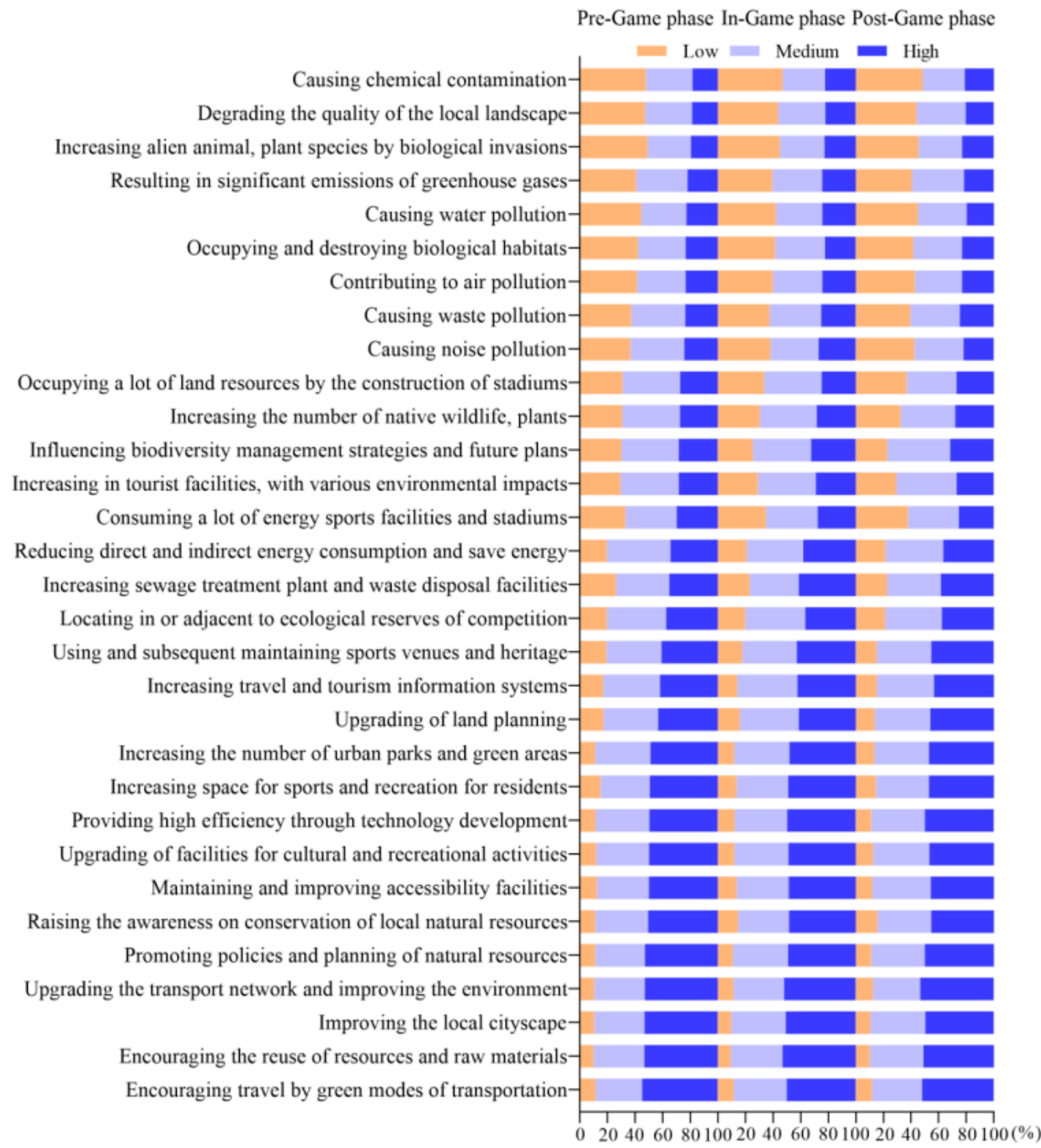

Figure 5. The perceived environmental sustainability of the 2022 Winter Olympics. $\mathrm{N}=806$; all items were assessed on a three-point scale $(1=$ low, 2 = medium, and 3 = high $)$.

Secondly, during the in-game phase, respondents also highly agreed about encouraging the reuse of resources and raw materials $(\mathrm{M}=2.44)$ and improving the local cityscape $(\mathrm{M}=2.41)$. Mixed responses were given regarding whether it would cause noise pollution $(\mathrm{SD}=0.80)$, water pollution $(\mathrm{M}=0.80)$, and chemical contamination $(\mathrm{SD}=0.80)$. Residents also expressed a high level of agreement toward the resource conservation (positive) dimension $(\mathrm{M}=2.39)$. Items with lower mean scores (below 1.8) were also associated with causing chemical contamination, increasing alien animal, plant species by biological invasions, and degrading the quality of the local landscape.

In the end, in the post-game phase, the respondents highly agreed on encouraging the reuse of resources and raw materials $(\mathrm{M}=2.41)$ and upgrading the transport network, and improving the environment $(\mathrm{M}=2.41)$. Mixed responses were given regarding whether it would occupy a lot of land resources by the construction of stadiums $(\mathrm{SD}=0.80)$, and 
increase alien animal, plant species by biological invasions $(\mathrm{SD}=0.80)$. Residents expressed a high level of agreement toward the living environment dimension $(\mathrm{M}=2.36)$. Items with lower mean scores (below 1.8) were also associated with causing chemical contamination.

Table 6. Descriptive statistics of the 2022 Winter Olympics environmental sustainability.

\begin{tabular}{|c|c|c|c|c|c|c|}
\hline \multirow{2}{*}{ Environmental Sustainability Dimensions \& Items } & \multicolumn{2}{|c|}{ Pre-Game Phase } & \multicolumn{2}{|c|}{ In-Game Phase } & \multicolumn{2}{|c|}{ Post-Game Phase } \\
\hline & $\mathbf{M}$ & SD & $\mathbf{M}$ & SD & $\mathbf{M}$ & SD \\
\hline Dimension 1: resource conservation (positive) & 2.41 & 0.53 & 2.39 & 0.53 & 2.36 & 0.54 \\
\hline Raising the awareness on conservation of local natural resources & 2.39 & 0.68 & 2.34 & 0.72 & 2.30 & 0.72 \\
\hline Promoting policies and planning of natural resources & 2.41 & 0.69 & 2.38 & 0.68 & 2.39 & 0.68 \\
\hline Encouraging the reuse of resources and raw materials & 2.43 & 0.67 & 2.44 & 0.66 & 2.41 & 0.67 \\
\hline Dimension 2: resource conservation (negative) & 1.96 & 0.76 & 1.91 & 0.76 & 1.90 & 0.80 \\
\hline Occupying a lot of land resources by the construction of stadiums & 1.96 & 0.76 & 1.91 & 0.76 & 1.90 & 0.80 \\
\hline Dimension 3: energy use & 2.23 & 0.45 & 2.21 & 0.45 & 2.20 & 0.44 \\
\hline Consuming a lot of energy by sports facilities and stadiums & 1.97 & 0.79 & 1.93 & 0.79 & 1.88 & 0.79 \\
\hline Reducing direct and indirect energy consumption and saving energy & 2.15 & 0.72 & 2.17 & 0.75 & 2.15 & 0.75 \\
\hline Providing high efficiency through technology development & 2.38 & 0.69 & 2.37 & 0.70 & 2.39 & 0.68 \\
\hline Encouraging travel by green modes of transportation & 2.43 & 0.69 & 2.38 & 0.68 & 2.40 & 0.69 \\
\hline Dimension 4: living environment & 2.39 & 0.50 & 2.38 & 0.49 & 2.36 & 0.49 \\
\hline Improving the local cityscape & 2.42 & 0.68 & 2.41 & 0.66 & 2.39 & 0.67 \\
\hline Increasing the number of urban parks and green areas & 2.37 & 0.68 & 2.36 & 0.69 & 2.33 & 0.70 \\
\hline Maintaining and improving accessibility facilities & 2.37 & 0.70 & 2.35 & 0.71 & 2.34 & 0.68 \\
\hline Upgrading the transport network and improving the environment & 2.42 & 0.68 & 2.40 & 0.69 & 2.41 & 0.70 \\
\hline Upgrading of facilities for cultural and recreational activities & 2.38 & 0.69 & 2.37 & 0.69 & 2.34 & 0.69 \\
\hline Dimension 5: environmental pollution & 1.81 & 0.61 & 1.84 & 0.63 & 1.79 & 0.62 \\
\hline Contributing to air pollution & 1.82 & 0.78 & 1.84 & 0.79 & 1.80 & 0.79 \\
\hline Causing water pollution & 1.78 & 0.79 & 1.82 & 0.80 & 1.75 & 0.77 \\
\hline Causing waste pollution & 1.86 & 0.77 & 1.87 & 0.78 & 1.85 & 0.79 \\
\hline Causing noise pollution & 1.88 & 0.77 & 1.89 & 0.80 & 1.79 & 0.78 \\
\hline Causing chemical contamination & 1.70 & 0.76 & 1.75 & 0.80 & 1.73 & 0.79 \\
\hline Resulting in significant emissions of greenhouse gases & 1.81 & 0.77 & 1.85 & 0.79 & 1.81 & 0.77 \\
\hline Dimension 6: tourism resources (positive) & 2.30 & 0.61 & 2.32 & 0.58 & 2.30 & 0.58 \\
\hline Increasing travel and tourism information systems & 2.25 & 0.73 & 2.28 & 0.70 & 2.28 & 0.71 \\
\hline Increasing space for sports and recreation for residents & 2.34 & 0.73 & 2.35 & 0.71 & 2.32 & 0.71 \\
\hline Dimension 7: tourism resources (negative) & 1.85 & 0.63 & 1.89 & 0.64 & 1.87 & 0.63 \\
\hline Increasing in tourist facilities, with various environmental impacts & 1.99 & 0.76 & 2.00 & 0.76 & 1.98 & 0.75 \\
\hline Degrading the quality of the local landscape & 1.71 & 0.76 & 1.78 & 0.78 & 1.76 & 0.77 \\
\hline Dimension 8: biodiversity & 1.93 & 0.51 & 1.96 & 0.50 & 1.96 & 0.50 \\
\hline Locating in or adjacent to ecological reserves of competition & 2.18 & 0.74 & 2.17 & 0.73 & 2.16 & 0.75 \\
\hline Occupying and destroying biological habitats & 1.81 & 0.79 & 1.81 & 0.78 & 1.81 & 0.78 \\
\hline Increasing the number of native wildlife, plants & 1.97 & 0.76 & 1.98 & 0.77 & 1.96 & 0.78 \\
\hline Increasing alien animal, plant species, with biological invasions & 1.70 & 0.77 & 1.78 & 0.79 & 1.77 & 0.80 \\
\hline Influencing biodiversity management strategies, future plans & 1.98 & 0.77 & 2.07 & 0.76 & 2.09 & 0.73 \\
\hline Dimension 9: institutional decision-making capacity & 2.19 & 0.56 & 2.23 & 0.55 & 2.26 & 0.54 \\
\hline Increasing sewage treatment plant and waste disposal facilities & 2.09 & 0.78 & 2.18 & 0.78 & 2.16 & 0.77 \\
\hline Upgrading of land planning & 2.26 & 0.73 & 2.25 & 0.72 & 2.32 & 0.70 \\
\hline Using and subsequently maintaining sports venues and heritage & 2.21 & 0.75 & 2.25 & 0.74 & 2.30 & 0.72 \\
\hline
\end{tabular}

Note: $\mathrm{N}=806$; all items were assessed on a three-point scale $(1=$ low, $2=$ medium, and $3=$ high $)$.

We also used three models to test H3. For the pre-game, in-game, and post-game phases, after estimating Models 7 to 9, we regressed host city sustainability on the dimension of Winter Olympics social sustainability to test H3. In Table 7, the result showed that resource conservation (positive) $(p<0.001)$, energy use $(p<0.001)$, living environment $(p<0.001)$, environmental pollution $(p<0.01$ and 0.05$)$, and biodiversity $(p<0.001)$ exerted significantly positive effects on host city sustainability $\left(R^{2}=0.584,0.534,0.580, F=120.786\right.$, 103.444, 124.567). Thus, H3 was mostly supported.

\subsection{Winter Olympics' Role in the Host City Sustainability}

Ten general public indicators (i.e., economic efficiency, transport efficiency, public safety, social welfare, education, living comfort, water use, resource self-sufficiency, ecological sustainability, and environmental management) were adopted by this study as indicators of urban sustainability (Table 8) [78]. As shown in the table, the agreement level of economic efficiency was high in all three phases $(\mathrm{M}=2.63 ; 2.47 ; 2.43$, respectively), while 
the agreement level of transportation efficiency and resource self-sufficiency was higher in the pre-game ( $\mathrm{M}=2.41,2.40)$ and in-game phases $(\mathrm{M}=2.44,2.45)$, and the agreement level of living comfort was higher in the in-game $(M=2.43)$ and post-game $(M=2.44)$ phases.

Table 7. Regression results of environmental sustainability of the 2022 Winter Olympics.

\begin{tabular}{|c|c|c|c|}
\hline Independent Variables & Pre-Game Phase Model 7 (Std $\beta$ ) & In-Game Phase Model 8 (Std $\beta$ ) & Post-Game Phase Model 9 (Std $\beta$ ) \\
\hline Resource conservation (positive) & $0.264^{* * *}$ & $0.229 * * *$ & $0.237 * * *$ \\
\hline Resource conservation (negative) & 0.064 * & 0.032 & -0.001 \\
\hline Energy use & $0.131 * * *$ & $0.128^{* * *}$ & $0.156^{* * *}$ \\
\hline Living environment & $0.199 * * *$ & $0.186^{* * *}$ & $0.195^{* * *}$ \\
\hline Environmental pollution & $0.111^{* *}$ & $0.079 *$ & $0.103^{* *}$ \\
\hline Tourism resources (positive) & $0.125^{* * *}$ & 0.053 & $0.131^{* * *}$ \\
\hline Tourism resources (negative) & 0.002 & 0.016 & $0.076 *$ \\
\hline Biodiversity & $0.205^{* * *}$ & $0.217^{* * *}$ & $0.160 * * *$ \\
\hline Institutional decision-making capacity & 0.056 & $0.164^{* * *}$ & $0.119^{* * *}$ \\
\hline$R^{2}$ & 0.584 & 0.534 & 0.580 \\
\hline$F$ & 126.786 & 103.444 & 124.567 \\
\hline
\end{tabular}

Note: ${ }^{*}, * * * * *$ Significant at $p<0.05, p<0.01, p<0.001$, respectively.

Table 8. Mean and standard deviation of urban sustainability.

\begin{tabular}{|c|c|c|c|c|c|c|}
\hline \multirow{2}{*}{ Dimensions \& Items } & \multicolumn{2}{|c|}{ Pre-Game Phase } & \multicolumn{2}{|c|}{ In-Game Phase } & \multicolumn{2}{|c|}{ Post-Game Phase } \\
\hline & $\mathbf{M}$ & SD & $\mathbf{M}$ & SD & $\mathbf{M}$ & SD \\
\hline Economic efficiency & 2.63 & 0.59 & 2.47 & 0.67 & 2.43 & 0.67 \\
\hline Transportation efficiency & 2.41 & 0.65 & 2.44 & 0.64 & 2.38 & 0.67 \\
\hline Public safety & 1.66 & 0.78 & 1.70 & 0.81 & 1.68 & 0.81 \\
\hline Social welfare & 2.22 & 0.71 & 2.26 & 0.70 & 2.28 & 0.70 \\
\hline Education & 2.20 & 0.74 & 2.25 & 0.72 & 2.26 & 0.71 \\
\hline Living comfort & 2.37 & 0.70 & 2.43 & 0.66 & 2.44 & 0.65 \\
\hline Water use & 1.89 & 0.79 & 1.87 & 0.80 & 1.83 & 0.80 \\
\hline Resource self-sufficiency & 2.40 & 0.69 & 2.45 & 0.66 & 2.38 & 0.72 \\
\hline Ecological sustainability & 2.04 & 0.78 & 2.09 & 0.78 & 2.10 & 0.78 \\
\hline Environmental management & 2.33 & 0.72 & 2.34 & 0.69 & 2.33 & 0.72 \\
\hline
\end{tabular}

Note: $\mathrm{N}=806$; all items were assessed on a three-point scale $(1=$ low, $2=$ medium, and $3=$ high $)$.

What's more, the 2022 Winter Olympics economic sustainability, social sustainability, and environmental sustainability were incorporated into the regression model as independent variables to assess Models 10 to 12. In Table 9, the analysis results showed that 2022 Winter Olympics economic sustainability ( $p<0.001$ in three phases, respectively), 2022 Winter Olympics social sustainability $(p<0.001)$, and 2022 Winter Olympics environmental sustainability $(p<0.001)$ exerted significantly positive effects on host city sustainability $\left(R^{2}=0.634,0.597,0.654\right.$ and $F=465.412,398.649,508.077$, respectively). Thus, H4 was mostly supported. In sum, the results suggest that the 2022 Winter Olympics economic sustainability, social sustainability, and environmental sustainability are critical predictors of host city sustainability.

Table 9. Regression results for predicting host city sustainability.

\begin{tabular}{cccc}
\hline Independent Variables & Pre-Game Phase Model 10 (Std $\beta$ ) & In-Game Phase Model 11 (Std $\beta$ ) & Post-Game Phase Model 12 (Std $\beta$ ) \\
\hline Economic sustainability & $0.203^{* * *}$ & $0.175^{* * *}$ & $0.200^{* * *}$ \\
Social sustainability & $0.348^{* * *}$ & $0.384^{* * *}$ & $0.380^{* * *}$ \\
Environmental sustainability & $0.364^{* * *}$ & $0.338^{* * *}$ & $0.370^{* * *}$ \\
$R^{2}$ & 0.634 & 0.597 & 0.654 \\
$F$ & 465.412 & 398.649 & 508.077 \\
\hline
\end{tabular}




\section{Discussion and Conclusions}

The 2022 Winter Olympics will have a catalytic effect on host city sustainable development. As one of the mega-events, the staging of the Winter Olympic Games always leaves a lasting impression on the host city or region and its inhabitants. Staging the Winter Olympic Games cannot be considered only positive or negative, but always has a variety of different outcomes [79-81]. However, each era has re-framed these outcomes according to its values and needs [82]. In recent years, scholars have become interested in the impact of the Winter Olympic Games on host cities $[83,84]$. Juxtaposed with the widespread and persuasive pro-Olympic message is a growing body of social science evidence that the Olympics have a fairly negative impact on host cities, especially on the marginalized populations that live there. Sustainability is therefore an important factor in the planning and delivery of the Olympic Games, an issue that deserves full attention and is seen as a pillar of Olympism [82].

In the economic dimension, the 2022 Winter Olympics will have a positive impact on the host city's sustainable development, especially in terms of industry development and investment benefits, also implying that Hypothesis 1 is confirmed. In terms of industry development, the 2022 Winter Olympics will not only boost tourism development and consumption but also lead the development of green industries in the city; while in terms of investment benefits, the 2022 Winter Olympics will provide more business opportunities for local businesses. As a means of urban marketing, to leverage the urban renewal projects sought by urban elites, Olympic bids are often accompanied by massive campaigns to promote the presumed economic and urban benefits of hosting the games [85-87].

In the social dimension, the 2022 Winter Olympics will positively influence the host city's sustainable development, meaning likewise that Hypothesis 2 is confirmed. This positive impact is particularly reflected in urban development, community development, and social welfare, respectively, as the 2022 Winter Olympics increases the city's international reputation and visibility, promotes a sense of pride and honor among residents, and expands the international perspective of residents. The Winter Olympics can have an impact on people's image, status, and sense of belonging to a place, and such impacts are often categorized as social impacts. The terms used to describe such impacts are usually place pride, civic pride, nationalism, patriotism, feel-good factor, reputation, image, and status [70,88-90]. It has been shown that hosting the Olympics can create a sense of enthusiasm and pride among the local population, giving an impression of community and solidarity that may even transcend social and ideological divisions [84]. Community support plays a key role in a city's successful bid for the Olympics, in the sense that residents provide a welcoming atmosphere for visitors, participate in orientation activities, and contribute to the development of volunteer resources [70,91].

In the environmental dimension, especially in the areas of resource conservation, energy use, and living environment, the 2022 Winter Olympics will positively influence the host city's sustainable development, equally implying that Hypothesis 3 is confirmed. In terms of resource conservation, the 2022 Winter Olympics will encourage the reuse of resources and raw materials; in terms of energy use, the 2022 Winter Olympics will encourage travel by green modes of transportation; and in terms of the living environment, the 2022 Winter Olympics will not only improve the local cityscape but also upgrade the transportation network and improve the environment. Previous studies related to these effects have been discussed in the theoretical background section of this paper.

Summing up the above three dimensions, the 2022 Winter Olympics will have a positive impact on host city sustainability, and again implying that Hypothesis 4 is confirmed. In conclusion, to summarize our findings, we can draw two conclusions. One, the 2022 Winter Olympic Games will be sustainable throughout the whole process. The whole process includes three phases named pre-game, in-game, and post-game, while sustainability will be fully reflected in all three phases. Two, the 2022 Winter Olympic Games will have a positive impact on the host city's sustainable development in all aspects, including economic, social, and environmental sustainability. We obtained firsthand data 
utilizing a questionnaire survey and studied the impact of the Winter Olympics on host city sustainable development systematically in three stages and in three dimensions at the same time, completely from the public's perspective. Nevertheless, perhaps the number of our respondents is not particularly large and is not a complete substitute for the actual situation. In addition, the number of items set in the three dimensions is not uniform, which may slightly interfere with the respondents' answers and cause slight bias in the final statistical results. As we said at the beginning of the results section, the 2022 Winter Olympics have not yet been held, and the results in the three time phases, especially the in-competition and post-competition results, are more reflective of respondents' perceptions and expectations of the possible future impact of the yet-to-be-held Winter Olympics. Such expectations or perceptions of respondents may change when the Winter Olympics are actually held, so the perceptions of residents can be collected here for further research during and after the actual Winter Olympics in the future. When we are enthusiastic about the influence of the 2022 Winter Olympics on host cities, we have to recall some few facts that limit enthusiasm (without denying some positive effects): (1) the decrease in the number of cities that bid for the games as an illustration of the decline of the perceived power of sporting events to really have a positive effect on host territories, (2) some facts that refute official commitment, i.e., during the 2010 Vancouver games, some trucks carrying snow counterbalanced the establishment of the Sustainable Development and Resource Management Commission; (3) the 2016 Winter Olympics strongly illustrated that many things still have to be done to manage sport facilities after hosting the event. Therefore, in the future study, we can also put ourselves in the public's shoes, ask and record the respondents' impressions of the Winter Olympics venue, explore their perceptions and attitudes toward the sustainability of the Winter Olympics, and study the role played by sustainable development goals in the Winter Olympics.

Author Contributions: G.H. took the main role in the design and execution of the survey, revising the paper; G.Y., writing-draft preparation and editing; C.C., review and editing. All authors have read and agreed to the published version of the manuscript.

Funding: This research was supported by The National Natural Science Foundation Of China (Beijing, China), grant number 41877529, The National Key R \& D Program of China, grant number 2019YFC0507501, and Guangxi Special Fund Project of Innovation Driven Development, grant number Gui Ke AA20161004.

Data Availability Statement: Not applicable.

Conflicts of Interest: The authors declare that they have no conflict of interest.

\section{References}

1. He, G.Z.; Zhang, Q.; Lv, Y.L. Eco environmental impacts of the Winter Olympic Games on host cities: A critical review. Acta Ecol. Sin. 2020, 40, 1129-1139. (In Chinese)

2. Liang, Y.W.; Wang, C.H.; Tsaur, S.H.; Yen, C.H.; Tu, J.H. Mega-event and urban sustainable development. IJEFM 2016, 7, 152-171. [CrossRef]

3. Essex, S.; Chalkley, B. Mega-sporting events in urban and regional policy: A history of the Winter Olympics. Plan. Perspect. 2004, 19, 201-204. [CrossRef]

4. Simona, S.; Giulio, P.M. Strategies, tools and opportunities for the development of a sustainable tourism: The case of the Torino 2006 Winter Olympic Games. In Proceedings of the 2006 First International Symposium on Environment Identities and Mediterranean Area, Corte-Ajaccio, France, 10-13 July 2006; pp. 361-366.

5. Azzali, S. The legacies of Sochi 2014 Winter Olympics: An evaluation of the Adler Olympic Park. Urban Res. Pract. 2017, 10, 329-349. [CrossRef]

6. International Olympic Committee. IOC-Sustainability-Report-2018; IOC: Lausanne, Switzerland, 2018; Volume 9-16, pp. 40-45.

7. Yeerkenbieke, G.; He, G.Z.; Lu, Y.L. Sustainable strategy of Winter Olympics from the perspective of the International Olympic Committee. J. Beijing Sport Univ. 2020, 43, 124-135. (In Chinese)

8. Huang, Q. An analysis of the 2022 Winter Olympic Games on the promotion of the integrated development of Beijing-TianjinHebei region. Peer 2016, 8, 456. (In Chinese)

9. Baade, R.A.; Matheson, V.A. The quest for the cup: Assessing the economic impact of the World Cup. Reg. Stud. 2004, 38, 343-354. [CrossRef] 
10. Lee, C.K.; Taylor, T. Critical reflections on the economic impact assessment of mega-event: The case of 2002 FIFA World Cup. Tour. Manag. 2005, 26, 595-603. [CrossRef]

11. Mair, J.; Whitford, M. An exploration of events research: Event topics, themes and emerging trends. IJEFM 2013, 4, 6-30. [CrossRef]

12. Ribeiro, T.; Biscaia, R.; Correia, A. The social impact of the 2016 Rio Olympic Games: Comparison of residents' pre- and post-event perceptions. Sport Bus. Manag. 2020. ahead-of-print.

13. Ribeiro, T.; Correia, A. The relationship between organizational issues and social impacts of Rio Olympic Games: A volunteer's perspective. J. Policy Res. Tour. Leis. Events 2021, 13, 124-145. [CrossRef]

14. Papanikos, G.T. The Participation Legacy at Olympic Games. Athens J. Sports 2020, 7, 251-262. [CrossRef]

15. Fairley, S.; Tyler, B.D.; Kellett, P.; D'Elia, K. The formula one Australian grand prix: Exploring the triple bottom line. Sport Manag. Rev. 2011, 14, 141-152. [CrossRef]

16. Andersson, T.D.; Lundberg, E. Commensurability and sustainability: Triple impact assessments of a tourism event. Tour. Manag. 2013, 37, 99-109. [CrossRef]

17. Scandizzo, P.L.; Pierleoni, M.R. Assessing the Olympic Games: The economic impact and beyond. J. Econ. Surv. 2018, 32, 649-682. [CrossRef]

18. Duignan, M.B.; Pappalepore, I.; Everett, S. The "summer of discontent": Exclusion and communal resistance at the London 2012 Olympics. Tour. Manag. 2019, 70, 355-367. [CrossRef]

19. Hiller, H.H.; Wanner, R.A. Public opinion in host Olympic cities: The case of the 2010 Vancouver Winter Games. Sociology 2011, 45, 883-899. [CrossRef]

20. Ritchie, B.W.; Chien, P.M.; Shipway, R. A Leg(acy) to stand on? A non-host resident perspective of the London 2012 Olympic legacies. Tour. Manag. 2020, 77, 104031. [CrossRef]

21. Collins, A.; Flynn, A. Measuring the environmental sustainability of a major sporting event: A case study of the FA Cup Final. Tour. Econ. 2008, 14, 751-768. [CrossRef]

22. Collins, A.; Munday, M.; Roberts, A. Environmental consequences of tourism consumption at major events: An analysis of the UK stages of the 2007 Tour de France. J. Travel Res. 2012, 51, 577-590. [CrossRef]

23. Jago, L.; Dwyer, L.; Lipman, G.; Van Lill, D.; Vorster, S. Optimising the potential of mega-events: An overview. IJEFM 2010, 1 , 220-237. [CrossRef]

24. Cornelissen, S.; Swart, K. The 2010 football world cup as a political construct: The challenge of making good on an African promise. Sociol. Rev. 2006, 54, 108-123. [CrossRef]

25. Chang, P.C.; Singh, K.K. Risk management for mega events: The 1988 Olympic Winter Games. Tour. Manag. 1990, 11, 45-52. [CrossRef]

26. Gaudette, M.; Roult, R.; Lefebvre, S. Winter Olympic Games, cities, and tourism: A systematic literature review in this domain. J. Sport Tour. 2017, 21, 287-313. [CrossRef]

27. Terret, T. Gold medals and white economy: Winter Olympic Games and the making of the French elite (1959-2013). Int. J. Hist. Sport 2015, 32, 565-583. [CrossRef]

28. Bottero, M.; Sacerdotti, S.L.; Mauro, S. Turin 2006 Olympic Winter Games: Impacts and legacies from a tourism perspective. J. Tour. Cult. Chang. 2012, 10, 202-217. [CrossRef]

29. Spilling, O.R. Mega event as strategy for regional development: The case of the 1994 Lillehammer Winter Olympics. Entrep. Reg. Dev. 1996, 8, 321-344. [CrossRef]

30. Kariel, H.G.; Kariel, P.E. Tourist developments in the Kananaskis Valley area, Alberta, Canada, and the impact of the 1988 Winter Olympic Games. Mt. Res. Dev. 1988, 8, 1-10. [CrossRef]

31. Mount, J.; Leroux, C. Assessing the effects of a mega event: A retrospective study of the impact of the Olympic games on the Calgary business sector. Fest. Manag. Event Tour. 1994, 2, 15-23. [CrossRef]

32. Baade, R.A.; Baumann, R.W.; Matheson, V.A. Slippery Slope? Assessing the economic impact of the 2002 Winter Olympic Games in Salt Lake City, Utah. Reg. Dev. 2010, 31, 81-92.

33. Jiao, L.L.; Zhang, Y.C.; Zhang, Q. Influence on the host city economic development of the 2022 Winter Olympic Games and its market operation research. Hubei Sports Sci. 2016, 35, 31-34. (In Chinese)

34. Yang, W.F. The impact of the 2022 Winter Olympic Games on the synergistic development of the Beijing-Zhangjiakou region. Cons. Guide 2016, 12, 46-47. (In Chinese)

35. Müller, M. Introduction: Winter Olympics Sochi 2014: What is at stake? Eeat Eur. Politics 2014, 30, 153-157. [CrossRef]

36. Terret, T. The Albertville Winter Olympics: Unexpected legacies failed expectations for regional economic development. Int. J. Hist. Sport 2008, 25, 1903-1921. [CrossRef]

37. Wang, H.B. The 2022 Beijing Winter Olympic Games: Opportunities and challenges for improving urban management. Urban Manag. Technol. 2017, 1, 28-31. (In Chinese)

38. Deccio, C.; Baloglu, S. Nonhost community resident reactions to the 2002 Winter Olympics: The spillover impacts. J. Travel Res. 2002, 41, 46-56. [CrossRef]

39. Ritchie, J.R.B.; Lyons, M.M. Olympulse VI: A post event assessment of resident reaction to the XV Olympic Winter Games. J. Travel Res. 1990, 28, 14-23. [CrossRef]

40. Waitt, G. Social impacts of the Sydney Olympics. Ann. Tour. Res. 2003, 30, 194-215. [CrossRef] 
41. Zhou, Y.; Ap, J. Residents' perceptions towards the impacts of the Beijing 2008 Olympic Games. J. Travel Res. 2009, 48, 78-91. [CrossRef]

42. Ritchie, J.R.B.; Smith, B.H. The impact of a mega event on host region awareness: A longitudinal study. J. Travel Res. 1991, 30, 3-10. [CrossRef]

43. Miyoshi, K.; Sasaki, M. The Long-term impacts of the 1998 Nagano Winter Olympic Games on economic and labor market outcomes. Asian Econ. Policy Rev. 2016, 11, 43-65. [CrossRef]

44. Billings, A.; Brown, K.; Brown, M.N. Sports draped in the American flag: Impact of the 2014 Winter Olympic telecast on nationalized attitudes. Mass Commun. Soc. 2015, 18, 377-398. [CrossRef]

45. VanLuijk, N.; Frisby, W. (Re)Framing of protest at the 2010 Winter Olympic Games. Int. J. Sport Policy Politics 2012, 4, 343-359. [CrossRef]

46. VanWynsberghe, R.; Derom, I.; Maurer, E. Social leveraging of the 2010 Olympic Games: Sustainability in a city of Vancouver initiative. J. Policy Res. Tour. Leis. Events 2012, 4, 185-205. [CrossRef]

47. Cantelon, H.; Letters, M. The making of the IOC environmental policy as the third dimension of the Olympic movement. Int. Rev. Soc. Sport 2000, 35, 294-308. [CrossRef]

48. Alberts, H.C. The reuse of sports facilities after the Winter Olympic Games. Focus Geogr. 2011, 54, 24-32. [CrossRef]

49. Zhao, Y.Z.; Gu, F.J.; Ji, G.; Liu, Y.Z. Discussion on the management of the mine geological environment along the Winter Olympics traffic corridor-Taking an iron ore mine of Sandaoying Iron Ore Co. Ltd. as an example. Urban Eco. 2016, 11, 26-29. (In Chinese)

50. Zhou, B. Research on the green development strategy of Northern Beijing under the background of the 2022 Winter Olympic Games. Chin. J. Environ. Manag. 2018, 10, 121-125. (In Chinese)

51. Kuziak, N. The Environmental Impact of the Winter Olympic Games; University of Ottawa: Ottawa, ON, Canada, $1995 ; \mathrm{pp} .65-103$.

52. Laiolo, P.; Rolando, A. Forest bird diversity and ski runs: A case of negative edge effect. Anim. Conserv. 2005, 8, 9-16. [CrossRef]

53. Prudnikova, N. Environmental Problems and unintended consequences of the Winter Olympic Games: A case study of Sochi 2014. J. Policy Res. Tour. Leis. Events 2012, 4, 211-214. [CrossRef]

54. Rutty, M.; Scott, D.; Steiger, R.; Johnson, P. Weather risk management at the Olympic Winter Games. Curr. Issues Tour. 2015, 18, 931-946. [CrossRef]

55. Scalenghe, R.; Fasciani, G. Soil Heavy Metals Patterns in the Torino Olympic Winter Games Venue (E.U.). Soil. Sediment. Contam. 2008, 17, 205-220. [CrossRef]

56. Sobol, A.L. No medals for Sochi: Why the environment earned last place at the 2014 Winter Olympic Games, and how host cities can score a green medal in the future. Villanova Environ. Law J. 2015, 26, 169-192.

57. Traversi, D.; Degan, R.; Marco, R.D.; Gilli, G.; Pignata, C.; Ponzia, M.; Rava, M.; Sessarego, F.; Villani, S.; Bono, R. Mutagenic properties of PM2.5 air pollution in the Padana Plain (Italy) before and in the course of XX Winter Olympic Games of Torino 2006. Environ. Int. 2008, 34, 966-970. [CrossRef]

58. Roper, T. Producing environmentally sustainable Olympic Games and "greening" major public events. Glob. Urban Dev. 2006, 2, 1-5.

59. International Olympic Committee. Sustainability Strategy; IOC: Lausanne, Switzerland, 2017; Volume 22-25, pp. 30-40.

60. Ma, S.C.; Egan, D.; Rotherham, I.; Ma, S.M. A framework for monitoring during the planning stage for a sports mega-event. J. Sustain. Tour. 2011, 19, 79-96. [CrossRef]

61. Molnar, A. The geo historical legacies of urban security governance and the Vancouver 2010 Olympics. Geogr. J. 2015, 181, 235-241. [CrossRef]

62. Pitts, A.; Liao, H.W. An assessment technique for the evaluation and promotion of sustainable Olympic design and urban development. Build. Res. Inf. 2013, 41, 722-734. [CrossRef]

63. Wang, M. The boosting effect and valley effect of the Olympic Games. J. Nanjing Sport Inst. 2017, 31, 93-98. (In Chinese)

64. Yang, B.F.; Liu, D.B.; Jing, W. Historical evolution of the Winter Olympics and urban development. Sports Cult. Guide 2014, 8, 173-176. (In Chinese)

65. Kim, H.J.; Gursoy, D.; Lee, S.B. The impact of the 2002 World Cup on South Korea: Comparisons of pre- and post-games. Tour. Manag. 2006, 27, 86-96. [CrossRef]

66. Kaplanidou, K.; Karadakis, K.; Gibson, H.; Thapa, B.; Walker, M.; Geldenhuys, S.; Coetzee, W. Quality of life, event impacts, and mega-event support among South African residents before and after the 2010 FIFA World Cup. J. Travel Res. 2013, 52, 631-645. [CrossRef]

67. Aitken, C.E.; Ritchie, J.R.B. Olympulse I: A survey of resident views concerning the XV Olympic Winter Games in Calgary. Crit. Rev. Immunol. 1983, 17, 77-88.

68. Ritchie, J.R.B.; Aitken, C.E. Olympulse II evolving resident attitudes toward the 1988 Olympic Winter Games. J. Travel Res. 1985, 23, 28-33. [CrossRef]

69. Ritchie, J.R.B.; Lyons, M.M. Olympulse III/ Olympulse IV: A mid term report on resident attitudes concerning the XV Olympic Winter Games. J. Travel Res. 1987, 26, 18-26. [CrossRef]

70. Karadakis, K.; Kaplanidou, K. Legacy perceptions among host and non-host Olympic Games residents: A longitudinal study of the 2010 Vancouver Olympic Games. Eur. Sport Manag. Q. 2012, 12, 243-264. [CrossRef]

71. Müller, M. Popular perception of urban transformation through mega events: Understanding support for the 2014 Winter Olympics in Sochi. Environ. Plan. C Gov. Policy 2012, 30, 693-711. [CrossRef] 
72. He, G.Z.; Yeerkenbieke, G.; Baninla, Y. Public Participation and Information Disclosure for Environmental Sustainability of 2022 Winter Olympics. Sustainability 2020, 12, 7712. [CrossRef]

73. Cohen, J.; Cohen, P.; West, S.G.; Aiken, L.S. Applied multiple regression/correlation. J. R. Stat. Soc. 2010, 52, 691.

74. Hall, C.M. The definition and analysis of hallmark tourist events. GeoJournal 1989, 19, 263-268. [CrossRef]

75. May, V. Environmental implications of the 1992 Winter Olympic Games. Tour. Manag. 1995, 16, 269-275. [CrossRef]

76. Dolles, H.; Söderman, S. Mega-sporting events in asia-Impacts on society, business and management: An introduction. Asian Bus. Manag. 2008, 7, 147-162. [CrossRef]

77. Song, S.; Zhang, S.; Wang, T.Y.; Meng, J.; Zhou, Y.Q.; Zhang, H. Balancing conservation and development in Winter Olympic construction: Evidence from a multi-scale ecological suitability assessment. Sci. Rep. 2018, 8, 14083. [CrossRef]

78. Huang, S.L.; Wu, S.C.; Chen, W.B. Ecosystem, environmental quality and ecotechnology in Taipei metropolitan region. Ecol. Eng. 1995, 4, 233-248. [CrossRef]

79. Florida-James, G.; Donaldson, K.; Stone, V. Athens 2004: The pollution climate and athletic performance. J. Sports Sci. 2004, 22, 967-980. [CrossRef] [PubMed]

80. Peiser, B.; Reilly, T. Environmental factors in the summer Olympics in historical perspective. J. Sports Sci. 2004, $22,981-1002$. [CrossRef]

81. Streets, D.G.; Fu, J.S.; Jang, C.J.; Hao, J.M.; He, K.B.; Tang, X.Y.; Zhang, Y.H.; Wang, Z.F.; Li, Z.P.; Zhang, Q.; et al. Air quality during the 2008 Beijing Olympic Games. Atmos. Environ. 2007, 41, 480-492. [CrossRef]

82. Gold, J.R.; Gold, M.M. "Bring it under the legacy umbrella": Olympic host cities and the dhanging fortunes of the sustainability agenda. Sustainability 2013, 5, 3526-3542. [CrossRef]

83. Alberts, H.C. Berlin's failed bid to host the 2000 Summer Olympic Games: Urban development and the improvement of sports facilities. Int. J. Urban Reg. Res. 2010, 33, 502-516. [CrossRef]

84. Waitt, G.R.; Furrer, P. Sharing the spirit? Sociospatial polarization and expressed enthusiasm for the Olympic Games. Pacif. Tour. Rev. 2000, 3, 173-184.

85. Burbank, M.J.; Andranovich, G.; Heying, C.H. Mega-events, urban development, and public policy. Rev. Policy Res. 2010, 19, 179-202. [CrossRef]

86. Gold, J.R.; Gold, M.M. Olympic cities: Regeneration, city rebranding and changing urban agendas. Geogr. Compass 2008, 2, 300-318. [CrossRef]

87. Short, J.R. Globalization, cities and the Summer Olympics. City 2008, 12, 321-340. [CrossRef]

88. Atkinson, G.; Mourato, S.; Szymanski, S.; Ozdemiroglu, E. Are we willing to pay enough to 'back the bid'? Valuing the intangible impacts of London's bid to host the 2012 Summer Olympic Games. Urban Stud. 2008, 45, 419-444. [CrossRef]

89. Smith, A. Theorising the relationship between major sports events and social sustainability. J. Sport Tour. 2009, 14, 109-120. [CrossRef]

90. Hiller, H.H. Post-event outcomes and the post-modern turn. Eur. Sport Manag. Q. 2006, 6, 317-332. [CrossRef]

91. Fairley, S.; Cardillo, M.L.; Filo, K. Engaging volunteers from regional communities: Non-host city resident perceptions towards a mega-event and the opportunity to volunteer. Event Manag. 2016, 20, 433-447. [CrossRef] 